\title{
What the rat's nose tells the rat's mouth: Long delay aversion conditioning with aqueous odors and potentiation of taste by odors
}

\author{
BURTON M. SLOTNICK \\ American University, Washington, D.C. \\ FRED WESTBROOK \\ University of New South Wales, Sydney, New South Wales, Australia \\ and \\ FRANCES M. C. DARLING \\ American University, Washington, D.C.
}

\begin{abstract}
In Experiment 1, olfactory bulbectomized and control rats were trained using operant conditioning to determine the taste threshold of aqueous amyl acetate. Concentrations below gustatory threshold were used in Experiments 2-5 to compare the effectiveness of odors with various concentrations of saccharin as cues for illness. The results showed the following: (1) The effectiveness of odor and taste was directly related to concentration; (2) the strength of an aversion to a concentration of taste could be matched by an appropriate concentration of an odor; (3) odor was as effective as taste with CS-US delays of $4 \mathrm{~h}$; and (4) an effective odor potentiated an aversion to an otherwise ineffective taste. The results challenge the privileged role accorded tastes in food aversion learning and the manner in which tastes are held to interact with odors according to the sensory-and-gate channeling analysis of potentiation (Rusiniak, Hankins, Garcia, \& Brett, 1979).
\end{abstract}

Garcia and Rusiniak (1980) told the story of a foraging rat who sniffs out a tasty food that has been laced with a slow-acting but undetectable poison. After eating some of the food, the rat uses its nose to avoid predators and the scent-marked territories of conspecifics on its return to the nest, where it sniffs, grooms, and copulates with its mate. The rat becomes ill from the effects of the poison but survives. Subsequently, the rat avoids the smell of the poisoned food. How did the rat know which of the several smells was associated with illness? Garcia and Rusiniak's answer to this question was that smells are ineffective cues for illness unless experienced in combination with a taste. When this occurs, smells become just as effective as tastes in signaling illness. This answer is based on a theory of food avoidance learning (see, e.g., Garcia, Lasiter, Bermudez-Rattoni, \& Deems, 1985) that (1) identifies taste as the critical conditioned stimulus (CS) for the internal changes produced by ingestion and (2) holds that a taste gates an associated smell into the feeding system, imbuing that smell with taste-like properties (see Domjan, 1983; LoLordo \& Droungas, 1989, for discussion).

In their seminal study of the cue-to-consequence effect, Garcia and Koelling (1966) reported that illness conditioned an aversion to a taste, but not to an audiovisual CS,

This research was supported by grants from the Australian Research Council and the NIMH. Correspondence should be addressed to B. M. Slotnick, Department of Psychology, American University, Washington, DC 20016 (e-mail: slotnic@american.edu). whereas a shock unconditioned stimulus (US) conditioned avoidance of the audiovisual CS, but not of the taste. Garcia and his associates (e.g., Garcia, McGowan, \& Green, 1972; Garcia, Hankins, \& Rusiniak, 1974; Garcia et al., 1985) linked these cue-to-consequence effects with the biological relevance of the CSs for the USs. Thus, toxins in the blood or gut are held to activate an internal or gut-defense system that selectively conditions aversions to tastes, whereas peripheral pain engages an external or skin-defense system that conditions avoidance of antecedent visual or auditory cues. The status of odors with respect to these systems is ambiguous, since odors can provide the rat with information about either food or predators. However, the status of a smell is disambiguated by the presence of a taste that functions to gate the smell into the internal system, thereby imbuing its associated smell with taste-like properties.

This sensory-and-gate channeling analysis has been invoked to explain the potentiation of odor aversion learning by a taste. For example, Rusiniak, Hankins, Garcia, and Brett (1979) reported that an almond odor was a weak cue for illness, whereas the taste of saccharin was a strong cue. However, when the almond was presented in compound with the saccharin, poisoned rats acquired an aversion to the almond that was just as strong as that shown to the taste. The taste was said to have potentiated odor aversion learning. The potentiation of odor aversion learning by a poisoned taste has been confirmed by other investigators (e.g., Bouton, Jones, McPhillips, \& Swartzen- 
truber, 1986; Westbrook, Homewood, Horn, \& Clarke, 1983 ) and shown to be dependent on the odor being conditioned in compound with the taste (Durlach \& Rescorla, 1980). Moreover, there have been reports (Kucharski \& Spear, 1985; Palmerino, Rusiniak, \& Garcia, 1980) that long intervals between the presentations of either a taste or an odor and illness resulted in taste, but not in odor, aversions. Nevertheless, these same intervals supported odor aversions that were just as strong as those to the taste when illness followed an odor-taste compound.

The present experiments examined this theory of food aversion learning, specifically, the claims that (1) taste is the critical CS for the internal or gut-defense system, and (2) taste gates associated odors into that system. We reasoned that the first of these claims is based on evidence that has confounded the taste modality with the fact that tastes are intrinsic attributes of the food or fluid consumed. Thus, tastes are more effective cues for illness than are odor vapors, which emanate from a separate location than that occupied by the ingesta (e.g., Rusiniak et al., 1979). But odors mixed with the drinking fluid are also more effective cues for illness than are odors located in a cup surrounding the drinking spout (Bouton et al., 1986). Therefore, the crucial point of comparison is the effectiveness of taste and odor cues when both constitute intrinsic attributes of the ingesta. Moreover, such a comparison must be accompanied by evidence that an odor mixed with the ingesta is indeed an odor without gustatory properties. Experiment 1 in the present series provides just such a demonstration, and Experiments 2 and 3 consist in a parametric study of the comparative effectiveness of odors and tastes as cues for immediate and delayed illness. The second claim made by this theory of food aversion learning is that the potentiation of odor aversion learning by a taste is mediated by the gating of the odor into the internal or gut-defense system by the taste. In the present study, we reasoned that this claim is based on evidence that has confounded taste as the critical cue for potentiation with the fact that tastes are highly effective cues for illness. Therefore, the crucial point of comparison is whether or not any other highly effective cue for illness can potentiate aversion learning to its associate in a compound. Experiments 4 and 5 in the present series sought to determine whether an odor mixed with the ingesta can potentiate taste aversions just as a taste can potentiate such odor aversions (see, e.g., Bouton et al., 1986; Durlach \& Rescorla, 1980).

\section{EXPERIMENT 1}

This experiment examined whether rats were able to detect the taste of odorants mixed with water. Amyl acetate was selected as the odorant because it has proved effective as a cue for illness in previous studies of odor aversion learning (e.g., Panhuber, 1982; Taukulis, 1974). However, the potential taste properties of liquid odorants have not been clearly established across a range of concentrations. Therefore, we trained normal and olfactory bulbectomized rats in an operant taste detection task and then tested their ability to detect different aqueous concentrations of amyl acetate. The highest concentration of amyl acetate used in this study $(.1 \%)$ is at the upper limit of solubility in water for this substance.

\section{Method}

\section{Subjects}

The subjects were 6 experimentally naive male Wistar rats obtained from the colony of specific pathogen-free rats maintained by the University of New South Wales. They weighed $250-300 \mathrm{~g}$ and were housed in a plastic box $(65 \times 40 \times 22 \mathrm{~cm})$ where pelleted food was continuously available. The box was kept in a colony room maintained on a normal 12:12-h light:dark cycle.

\section{Apparatus}

Rats were trained in a Plexiglas chamber $(25 \times 20 \times 15 \mathrm{~cm})$ with a stainless steel floor. A stainless steel drinking tube was located $2 \mathrm{~cm}$ from a $3-\mathrm{cm}$ hole in one wall of the chamber. The rat could extend its snout through the hole of the chamber and lick the tube. The drinking tube consisted of ten 21-gauge stainless steel tubes recessed $.2 \mathrm{~mm}$ within a 10 -gauge stainless steel tube that, in turn, was contained in a plastic tube. Three of the 21 -gauge tubes were used in this study, and each of these was connected by a stainless steel tube to a separate $10-\mathrm{ml}$ reservoir via a two-way Teflon body solenoid. Operation of a solenoid dispensed a small amount of liquid into the 10-gauge tube. Contacts between the floor and the metal end of the drinking tube were detected by a touch circuit (Field \& Slotnick, 1987). Training and testing procedures were controlled by an Apple IIe computer and digital interface.

\section{Procedures}

Surgery. Each rat was anesthetized intraperitoneally (ip) with Ketamine $(100 \mathrm{mg} / \mathrm{kg})$ and Xylazine $(10 \mathrm{mg} / \mathrm{kg})$ and placed into a stereotaxic instrument. In 3 rats, the olfactory bulbs were completely removed by aspiration using a fine-glass pipette. All nerves from the cribriform plate were sectioned and the lesions were extended into the anterior olfactory nucleus. The remaining rats were placed in the stereotaxic instrument but did not receive surgery. At the completion of testing, the bulbectomized rats were deeply anesthetized and perfused through the heart with saline followed by $10 \%$ formalin. The brains were removed and examined using a dissecting microscope. This examination showed that the olfactory bulbs were completely removed in each of the 3 experimental rats.

Discrimination training. Beginning 5 days after surgery, water intake was restricted to $10 \mathrm{ml} / \mathrm{day}$, and, 10 days later, rats were trained in a go/no-go discrimination procedure to lick at the tube to obtain a liquid sample. Their task was to maintain a minimum lick rate when the sample was water $\left(\mathrm{S}^{+}\right)$and to reduce their lick rate when they received a tastant or odorant $(\mathrm{S}-$ ). A trial was initiated by a lick response. One reward $(.01 \mathrm{ml}$ of tap water) was delivered after the 10th lick, and two .01-ml samples of the $S+$ or the $S-$ were delivered after an additional 25 licks. If the sample was water $(\mathrm{S}+)$, a minimum of 10 licks within the next $2 \mathrm{sec}$ produced a reward (.03 $\mathrm{ml}$ of water). If the sample was a tastant or liquid odorant $(\mathrm{S}-$ ), completing this requirement produced a punishment $(0.5-\mathrm{mA}$ shock to the tongue). On $\mathrm{S}+$ trials, criterion responses were scored as hits, whereas failures to make a criterion response were scored as misses. On $\mathrm{S}-$ trials, failing to make a criterion response was scored as a correct rejection, whereas a criterion response was scored as a false alarm. There were 60-200 trials in each session, and each block of 20 trials contained an equal number of $S+$ and $S-$ presentations. Assignment of the three channels of the liquid delivery system to water reward, water presentation $(S+)$, and taste or odor stimulus $(\mathrm{S}-)$ was varied over tasks. Between tasks, each channel was washed thoroughly with hot water.

Initially, each rat was trained to discriminate water $(\mathrm{S}+)$ from $100 \mathrm{mM}$ sucrose $(\mathrm{S}-$ ). Rats achieved $90 \%$ or better correct re- 
sponding on this task in one or two 200-trial training sessions. Rats were then trained using $50,25,12,8,4$, and $2 \mathrm{mM}$ sucrose as the $\mathrm{S}-$ stimulus in consecutive sessions, and performance accuracy was determined for each block of 20 trials. A minimum of 60 trials was given in each session. The session was terminated if a rat achieved $85 \%$ or higher correct responding in a block of 20 trials, or, failing that criterion, after 200 trials. When all rats had been tested on the $2 \mathrm{mM}$ sucrose detection task, each was retrained on the $25 \mathrm{mM}$ sucrose solution and then tested for its ability to detect aqueous solutions of $.1 \%$ and $.01 \%$ amyl acetate. If a rat failed to achieve criterion performance on the $.1 \%$ amyl acetate solution in two 200-trial sessions, it was retrained using $25 \mathrm{mM}$ sucrose as the $\mathrm{S}-$ stimulus and then tested on the $.01 \%$ amyl acetate solution. The sucrose retraining sessions were used to ensure stimulus control before a new test substance was employed. All solutions in this and the remaining experiments were made with tap water.

Student $t$ tests were used to compare the performance of control and bulbectomized rats. The measure used for these tests was the mean performance of each rat on each test solution.

\section{Results and Discussion}

The mean percents correct responding for control and olfactory bulbectomized rats averaged across blocks of 20 trials to the taste and odor stimuli are shown in Figure 1. Rats received extensive training on the $50 \mathrm{mM}$ su- crose detection task, and accuracy of each rat was greater than $85 \%$ during the final $100-200$ trials.

Each rat reached performance accuracy of $85 \%$ or higher in detecting the $50,25,12$, and $8 \mathrm{mM}$ sucrose solutions. Two of the olfactory bulbectomized rats and 2 of the controls achieved a score of at least $75 \%$ correct on the $4 \mathrm{mM}$ sucrose test, but all rats performed largely at chance on the $2 \mathrm{mM}$ test. There were no significant differences between bulbectomized rats and controls on the sucrose tests for total errors made to reach performance accuracy of $85 \%$ in a block of 20 trials.

When . $1 \%$ amyl acetate served as the $\mathrm{S}+$ stimulus, each of the olfactory bulbectomized rats performed largely at chance levels (scores of $40 \%-65 \%$ ) in each 20 -trial block of two 200-trial sessions (Figure 1), but each of the control rats acquired this discrimination within the first 20-60 training trials $[t(4)=20, p<.0001]$. Olfactory bulbectomized rats also performed at chance levels on the $.01 \%$ amyl acetate task but, again, controls achieved criterion performance in $20-60$ trials $[t(4)=$ $8.5, p<.01]$. Despite chance performance in the amyl acetate sessions, each of the olfactory bulbectomized rats performed at $85 \%-100 \%$ accuracy in the first 20 trials

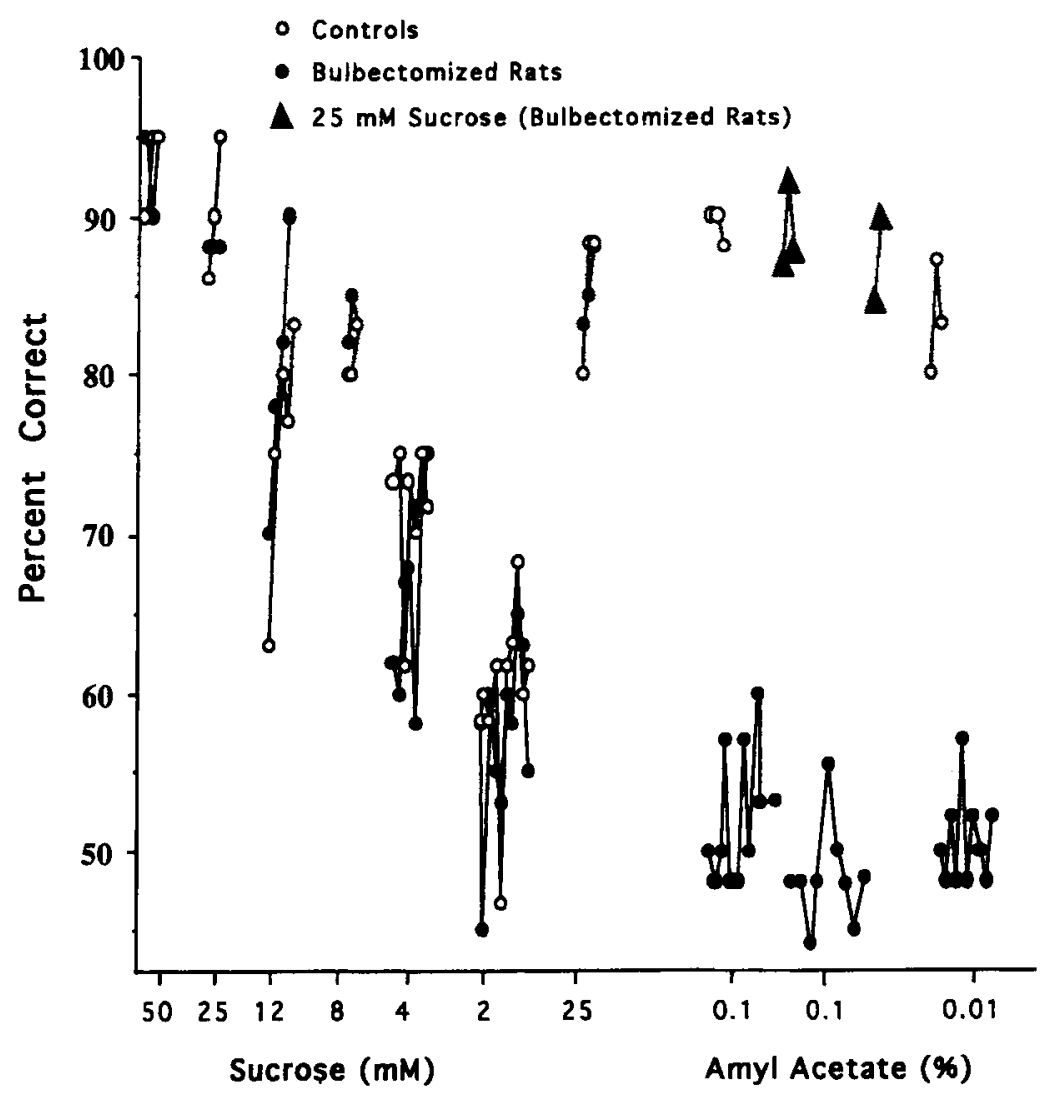

Figure 1. Experiment 1. Mean percent correct responding for control and olfactory bulbectomized rats tested with different concentrations of sucrose and amyl acetate. Note that olfactory bulbectomized rats were given two 200-trial sessions on the $.1 \%$ amyl acetate detection task. Tests on $25 \mathrm{mM}$ sucrose were given to experimental rats immediately after each session with amyl acetate. 
when the amyl acetate solution was replaced with $25 \mathrm{mM}$ sucrose.

These tests provided an efficient method for assessing detection of tastants. Each of the 6 rats acquired the task within a single 200 -trial session, when a relatively high concentration $(100 \mathrm{mM})$ of sucrose was used as the Sstimulus and each achieved criterion performance within 20-200 trials when tested on lower concentrations. The detection threshold for sucrose was between 2 and $8 \mathrm{mM}$ for these rats. Although this value is somewhat higher than values obtained with other operant discrimination procedures and more extensive training (Brosvic \& Slotnick, 1986), the procedure was clearly adequate to reveal detection of a near-threshold tastant. The fact that olfactory bulbectomized rats performed as well as controls on the tastant, but that only controls were able to reliably detect the $.1 \%$ and $.01 \%$ amyl acetate, provides evidence that this aqueous odorant has little, if any, gustatory properties.

\section{EXPERIMENT 2}

For purposes of exposition, the results of Experiments 2-4 are presented separately. However, these experiments were conducted simultaneously across a series of replications as rats became available in batches of 16-32. Experiment 2 compared the degree to which aqueous solutions of amyl acetate versus a tastant (saccharin) functioned as signals for immediate illness. Saccharin was selected as the tastant because of its extensive use in studies of taste aversion learning.

\section{Method}

\section{Subjects}

The subjects were 74 adult male Wistar rats weighing $296-382 \mathrm{~g}$. They had served as subjects in an experiment in which they had received a single shock exposure in an experimental chamber different from the test chambers used in the present study. The rats were housed as described in Experiment 1.

\footnotetext{
Apparatus

Four identical Plexiglas chambers $(12 \times 20 \times 15 \mathrm{~cm})$ were used. Each chamber had a stainless steel floor and a $27-\mathrm{cfm}$ ceiling fan that blew air from the laboratory into the chamber and through a 20 $\mathrm{mm}$-diameter hole located in the front wall of the chamber. The fan was used in an effort to minimize the presence of the odor vapor in the conditioning/test chamber and hence the effects of odor as a distal cue.

All solutions were presented to the rats in plastic tubes (made from $10-\mathrm{ml}$ disposable syringes) or glass tubes. The tubes were fitted with polypropylene stoppers and 8 -mm-diameter glass drinking tubes. The ends of the drinking tubes were fire polished and had a $3-\mathrm{mm}( \pm .2-\mathrm{mm})$ opening. Tongue contacts with the liquid in the tube were detected by a touch circuit connected between the floor of the test chamber and a 0.25 -mm-diameter stainless steel wire inserted into the drinking tube. The drinking tube was mounted at a $45^{\circ}$ angle outside the chamber so that the end of the glass sipper tube was approximately centered in the access hole in the front wall. Any fluid that leaked from the sipper tube fell outside of the chamber. Rats were trained and tested in squads of four, and licks on the tubes were recorded using an Apple lle computer, digital interface, and touch circuits. The control program, written in BASIC, sampled inputs from each tube 12 times/sec.
}

\section{Pretraining}

Rats were allowed 20 -min access to water each day for approximately 1 week and were then adapted to drinking tap water in the experimental chambers for 2-3 days. For each session, plastic boxes containing squads of rats were brought into the laboratory. The 4 rats in the first squad were placed in the chambers and allowed access to water for $3 \mathrm{~min}$. They were then removed to a holding cage, and the rats in the second squad were allowed access to water in the chambers. Each squad received a second 3-min session 5-10 min after the initial session. The rats were allowed 20 -min access to water in their home cages in the colony room approximately $20 \mathrm{~min}$ after the second drinking test.

\section{Conditioning and Test}

On the conditioning day, each rat was placed in the chamber for $6 \mathrm{~min}$ and allowed to drink a maximum of $10 \mathrm{ml}$ of the targeted fluid, removed to its home cage and, within $3 \mathrm{~min}$, injected ip with $128 \mathrm{mg} / \mathrm{kg}$ of $.15 \mathrm{M}$ lithium chloride ( $\mathrm{LiCl})$. Twenty minutes after being returned to the colony room, rats were given 20 -min access to water. On the day following conditioning, rats remained in the colony room, where they received 20 -min access to water. On the next day, they were given one session with water in the chambers and, beginning on the following day, they were tested for intake of the targeted fluid each day for 4 days (extinction tests). On each of these extinction tests, water was provided in the first 3-min test and the targeted fluid was in place on the second 3-min test.

\section{Groups}

On the conditioning day, six groups were presented with saccharin at a percent concentration of $.25(n=4), .1(n=5), .05(n=5)$, $.025(n=5), .0125(n=8)$, or $.00625(n=8)$. Eight groups of rats were presented with an aqueous solution of amyl acetate at percent concentration of .1 $(n=5), .01(n=4), .001(n=6), .0005(n=4)$, $.00025(n=4), .00005(n=4), .00001(n=6)$, or $.000005(n=6)$.

\section{Data Analysis}

A percent baseline intake score was calculated for each rat for each session by dividing the number of licks to the targeted fluid by the number of licks to the preceding water and multiplying by 100 . The results were evaluated using analysis of variance (ANOVA), and paired comparisons were made using Scheffé tests.

\section{Results and Discussion}

Rats consumed an average of $9.1 \mathrm{ml}$ (range of group means $=7.2-10 \mathrm{ml}$ ) of the odorant or tastant on the conditioning day, and differences among groups were not significant. Mean intake of the odorant or tastant on each of the four extinction tests as a percent of the preceding water intake on that session for rats in each group is shown in Figure 2.

One-way ANOVAs indicated a significant difference among groups on the 1 st extinction day for rats tested with saccharin $[F(5,29)=16.4, p<.0001]$ and amyl acetate $[F(7,31)=43.0, p<.0001]$ and, as shown in Figure 2, intake on each extinction day was related to concentration for each stimulus condition. A repeated measures ANOVA across all subjects revealed significant effects for groups $[F(13,60)=31.6, p<.0001]$ and extinction days $[F(3,180)=28.0, p<.0001]$ and a significant interaction $[F(39,180)=2.5, p<.0001]$.

The highest concentrations of each stimulus produced similar and strong inhibition of drinking on the first extinction test. A one-way ANOVA across all subjects for 

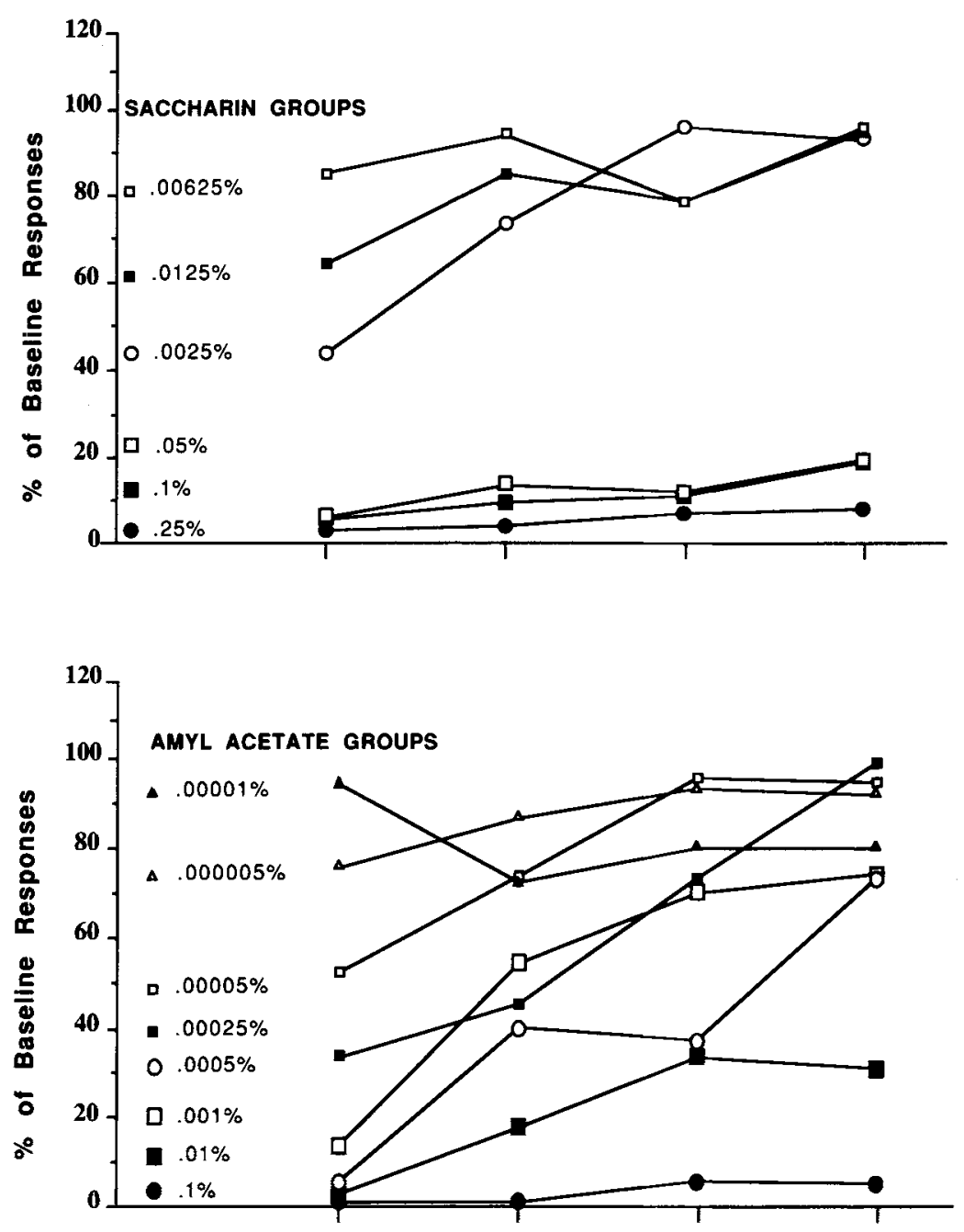

Figure 2. Experiment 2. Mean percent of baseline responding on each extinction test for groups conditioned and tested with saccharin (top graph) and amyl acetate (bottom graph).

the 1 st extinction day was significant $[F(13,60)=21.54$, $p<.0001]$. Of particular interest are the results of contrast tests between the saccharin and the odor groups. These revealed that the groups receiving the three highest concentrations of saccharin showed a greater suppression than did those that received the two lowest concentrations of amyl acetate, whereas groups that received the four highest concentrations of amyl acetate showed more suppression than did those receiving the three lowest concentrations of saccharin. But there were no significant differences between any of the three highest saccharin concentration groups and any of the four highest concentration amyl acetate groups. Thus, the higher concentrations of amyl acetate produced suppression on the first extinction test that was similar to that obtained with $.05 \%-.25 \%$ saccharin. As can be seen in Figure 2, the strength of an aversion obtained over a range of taste intensities can be matched using an amyl acetate odor of appropriate concentration.

Observation of the rats indicated that ventilation of the chamber did not prevent those in the high-concentration odor groups from using distal odor cues. Three rats receiving . $1 \%$ of amyl acetate and 2 rats receiving $.01 \%$ of amyl acetate sniffed at but did not lick the drinking tube in the first extinction test. Other rats in these groups often sniffed at the drinking tube and then backed away from it both before and after briefly sampling the fluid. This behavior was seldom observed in rats from other amyl acetate or saccharin groups.

The results of these two experiments confirm prior reports with tastants: The effectiveness of a chemical cue for illness is directly related to its concentration (e.g., Barker, 1976; Dragoin, 1971; Nachman \& Ashe, 1973). The results from the amyl acetate groups extend this finding to odors.

\section{EXPERIMENT 3}

Experiment 2 demonstrated that under appropriately controlled conditions, an odor may be just as effective as a taste for single-trial aversion learning when there is a very short delay between presentation of the cue and ill- 
ness. However, effective conditioning with long CS-US intervals is one of the hallmarks for the claimed primacy of tastes in aversion learning, and, thus, it is of particular interest for assessing this variable for odors. Therefore, Experiment 3 assessed whether odors are as effective as tastes in signaling illness when there are long intervals between the presentation of the CS and the illness.

Three groups of rats ( $n=4$ per group) were injected with $\mathrm{LiCl} 1,4$, or $12 \mathrm{~h}$ after exposure to a $.1 \%$ aqueous solution of amyl acetate, and six groups of rats $(n=4$ per group) were injected with $\mathrm{LiCl} 1,4$, or $12 \mathrm{~h}$ after exposure to a saccharin solution at a concentration of either . $1 \%$ or $.25 \%$. Test procedures were identical to those described in Experiment 2.

\section{Results and Discussion}

Rats consumed an average of $8.4 \mathrm{ml}$ on the conditioning day (range of group means $=6.3-9.8 \mathrm{ml}$ ), and differ-

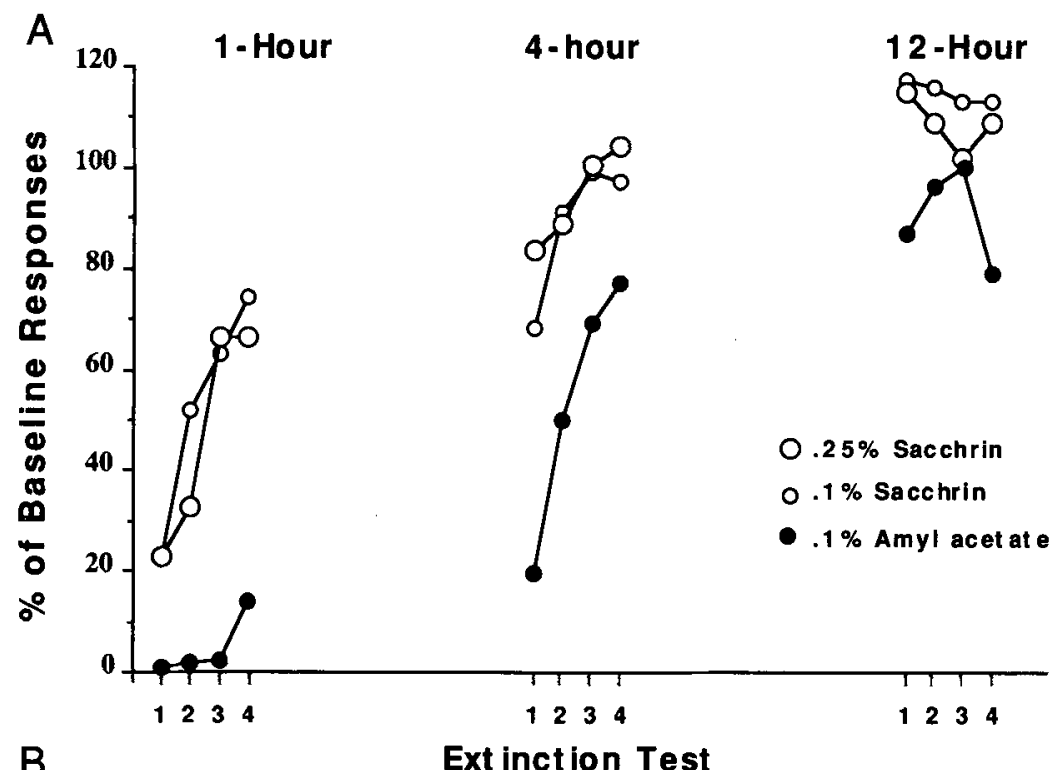

B

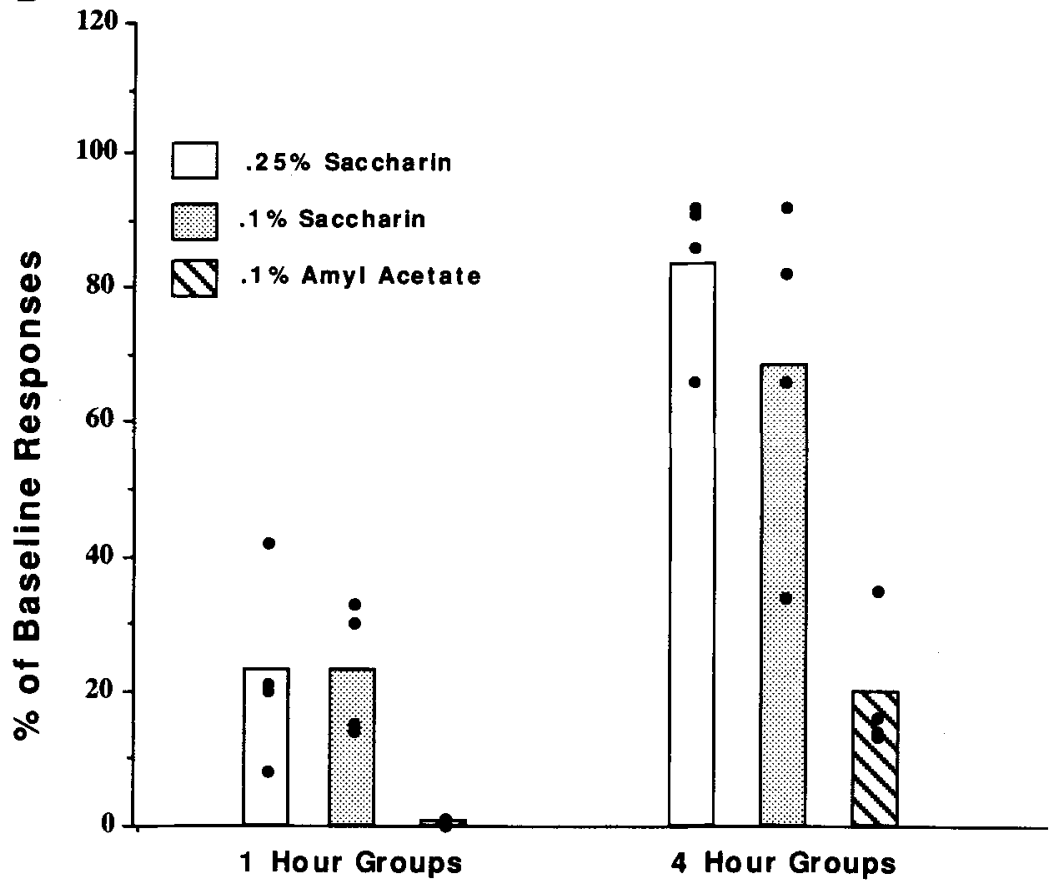

Figure 3. Experiment 3. Top graph: Mean percent of baseline responding on each extinction test for rats in the 1-, 4-, and 12-h CS-US delay conditions, for which .1\% saccharin, $.25 \%$ saccharin, or $.1 \%$ amyl acetate served as the conditioned stimulus. Bottom graph: mean percent of baseline responses for the same groups on the first extinction test. Solid dots show the scores of individual rats within each group. 
ences among groups were not significant. The mean percents of baseline intake for rats in each group over the four extinction tests are shown in Figure 3A, and means and individual scores for the first extinction test are shown in Figure 3B. Because there were no differences in performance on any of the extinction tests between the $.1 \%$ - and $.25 \%$-saccharin groups for the $1-, 4-$, or $12-\mathrm{h}$ delay conditions, these delay groups were collapsed across saccharin concentrations to form 1-, 4-, and 12-h saccharin groups for statistical analysis. Results of a twoway ANOVA for the first extinction test revealed a significant effect for type of stimulus $[F(1,26)=30.0, p<$ $.0001]$ and for delay $[F(2,26)=88.4, p<.0001]$. The interaction between stimulus and delay was significant $[F(2,36)=3.8, p<.05]$, reflecting the fact that suppression scores of the 4-h groups were more similar than those of the 1-h groups (Figure 3A). Contrast tests revealed that the 1-h groups had significantly more suppression than their respective 4-h groups, and the latter groups had significantly more suppression than their respective 12-h groups. Further, the 1- and 4-h amyl acetate groups had significantly more suppression than did the corresponding 1- and 4-h saccharin groups.

The performance of the 4-h amyl acetate group was almost identical to that of the 1-h taste groups over all extinction tests (Figure 3A). As shown in Figure 3A, the suppression observed among the rats injected with $\mathrm{LiCl}$ $1 \mathrm{~h}$ after presentation of the $.1 \%$ amyl acetate was considerable. Across the first three tests, these rats made only $0-8$ licks, and for the first extinction test, their performance did not differ from that of rats injected with $\mathrm{LiCl}$ immediately after presentation of amyl acetate in Experiment $2[t(8)=1.8]$. In contrast, rats injected with $\mathrm{LiCl} 1 \mathrm{~h}$ after exposure to either $.1 \%$ or $.25 \%$ saccharin showed significantly less suppression of intake on the first test than did the corresponding rats injected with $\mathrm{LiCl}$ immediately after these saccharin concentrations in Experiment $2[t(7)=2.4$ and $t(7)=2.7$, respectively].

\section{EXPERIMENT 4}

To assess the extent to which a stimulus of one modality (taste or odor) could potentiate one of another modality, rats were injected with $\mathrm{LiCl}$ immediately after presentation of a stimulus consisting of a combination of amyl acetate and saccharin. The rats were then tested in extinction on one component of the compound. For rats in Groups Sa-AA, the conditioning compound consisted of . $1 \%$ saccharin and amyl acetate at percent concentrations of $.001(n=5), .0005(n=4), .00025(n=4)$, $.00005(n=4), .00001(n=6)$, or $.000005(n=6)$. For rats in Groups AA-Sa, the conditioning compound was composed of . $1 \%$ amyl acetate and saccharin at percent concentrations of $.05(n=4), .025(n=8), .0125(n=$ $8)$, or $.00625(n=7)$. On the extinction test, rats in the Sa-AA groups were exposed to the concentration of the amyl acetate that they had received in compound with the $.1 \%$ saccharin, whereas rats in AA-Sa groups were tested on the concentration of saccharin that had been presented in compound with $.1 \%$ amyl acetate. Groups from Experiment 2, conditioned and tested only on the appropriate concentration of saccharin or amyl acetate, served as controls. The procedures used were identical to those described in Experiment 2.

\section{Results and Discussion}

On average, groups exposed to taste and odor compound stimuli consumed less fluid $(6.9 \mathrm{ml})$ on the conditioning day than did those exposed only to the weaker component of the compound $(8.7 \mathrm{ml})$. For groups in which saccharin was the potentiating stimulus, only the group with the highest percent concentration of amyl acetate (Group Sa-AA .001) consumed significantly $[t(9)=3.9]$ less fluid than did its control group (Group AA .001). For groups in which amyl acetate was the potentiating stimulus, intakes by Groups AA-Sa $.05[t(7)=3.1]$, AASa $.025[t(11)=4.4]$, and AA-Sa $.0125[t(14)=3.6]$ were significantly $(p \mathrm{~s}<.02$ for all) lower than those of their respective controls. Thus, combinations of . $1 \%$ saccharin and a moderate $(.001 \%)$ concentration of amyl acetate, or of .1\% amyl acetate and all but the weakest concentration of saccharin served to decrease consumption of the fluid on the conditioning day.

The results of major interest are the intakes of amyl acetate and saccharin on the extinction tests, which are shown in Figures $4 \mathrm{~A}$ and $4 \mathrm{~B}$, respectively. These figures also show the test intakes for rats conditioned to the amyl acetate alone or to saccharin alone, as described in Experiment 2. The effect of one element of the compound CS on conditioning to the other element was assessed by using $t$ tests to compare scores on the extinction test for the experimental group with its control group. As shown in Figure 4, fluid intake on the extinction test was negatively related to the concentration of the amyl acetate (Figure 4A) and the saccharin (Figure 4B). Potentiation of the odor aversion by saccharin was detected at the lowest $(.000005 \%)$ concentration of amyl acetate $[t(10)=$ 4], but not at higher concentrations of the odor, where, in fact, overshadowing was observed in Group Sa-AA .00025 $[t(6)=2.7]$. These findings confirm the results of Bouton et al. (1986), who reported that potentiation of an odor aversion by a taste is critically dependent on the use of an odor that is a weak cue for illness. However, the novel finding observed in the present experiment is that odors were capable of potentiating taste aversions. This potentiation was related to the concentration of the saccharin, since there was evidence for potentiation of the aversion to $.025 \%$ saccharin $[t(12)=6], .0125 \%$ saccha$\operatorname{rin}[t(14)=2.1]$, and $.00625 \%$ saccharin $[t(13)=2.5]$ by amyl acetate, but evidence for odor overshadowing of the aversion to .05 saccharin $[t(7)=2.5]$.

\section{EXPERIMENT 5}

This experiment had two aims. The first was to replicate the odor potentiation of aversion learning to saccharin with other tastes-sucrose and salt. Moreover, the design used in the previous experiment involved a com- 


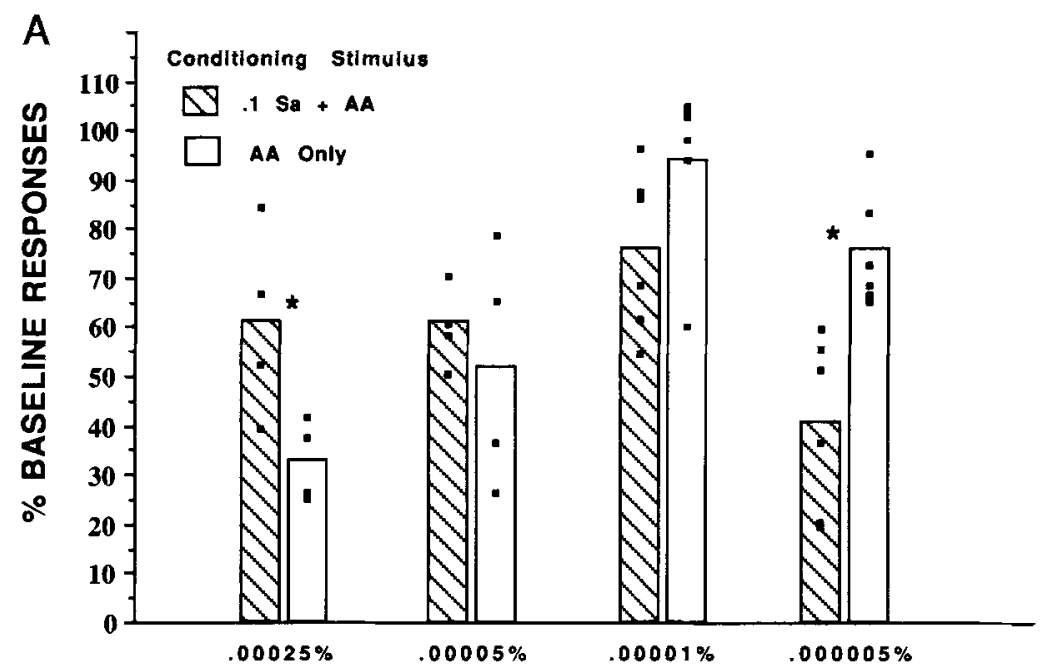

Amyl Acetate Test Stimulus

B

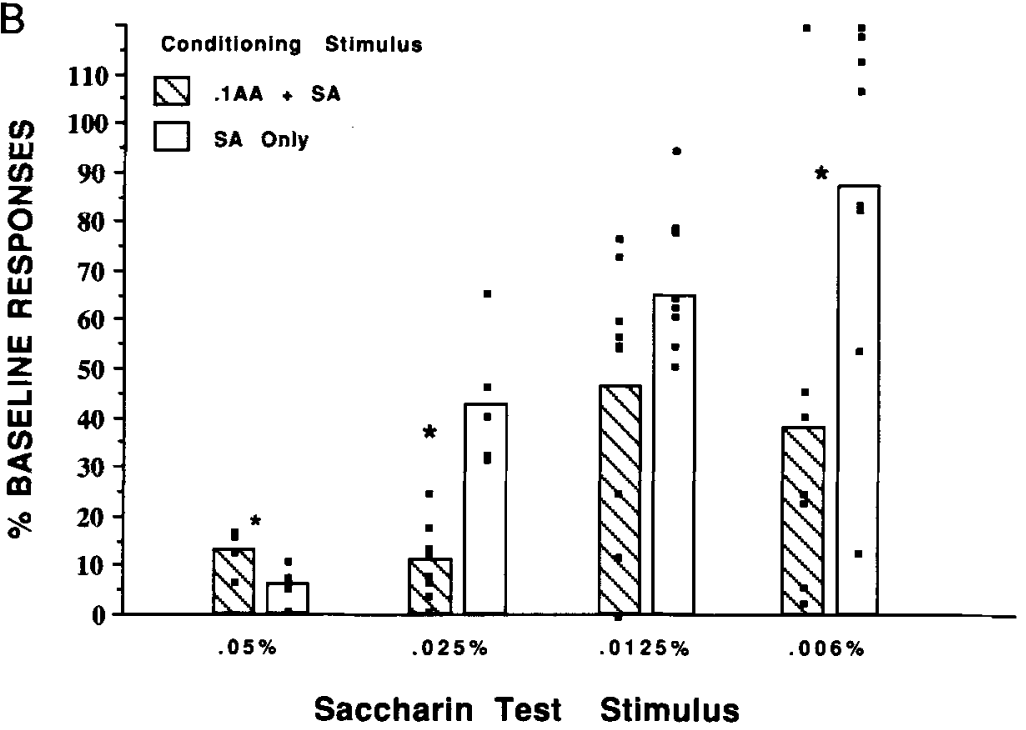

Figure 4. Experiment 4. Top graph: mean percent baseline responding on the extinction test for rats conditioned to a compound composed of $.1 \%$ saccharin and different concentrations of amyl acetate and tested only with that concentration of amyl acetate (diagonal striped bars). Control groups (open bars), conditioned and tested with amyl acetate only, were the same as those from Experiment 2. Bottom graph: mean percent baseline responding on the extinction test for rats conditioned to a compound composed of $.1 \%$ amyl acetate and different concentrations of saccharin and tested only with that concentration of saccharin (diagonal striped bars). Control groups (open bars), conditioned and tested with saccharin only, were the same as those from Experiment 2. *Significant between-group difference.

parison of taste aversion learning between a group conditioned to a taste and a group conditioned to that taste in compound with an odor. These groups differed not only in terms of the co-occurrence of the odor and the taste, but also in the occurrence of the odor and hence in the possibility that an aversion conditioned to the odor generalized to the taste (Durlach \& Rescorla, 1980). Therefore, the second aim of this experiment was to determine whether the odor potentiation of taste aversion learning was a result of the co-occurrence of the odor and taste or simply due to an odor having been conditioned in the course of the experiment. To distinguish between these alternatives, we selected the design used by Durlach and Rescorla, who studied taste potentiation of odor aversion learning. In our experiment, rats received $\mathrm{LiCl}$ on two occasions: after presentation of a compound composed 
of odor (amyl acetate) and Taste 1 and after presentation of a second taste (Taste 2). Taste 1 was sucrose and Taste 2 was $\mathrm{NaCl}$ for half of the rats, whereas Taste 1 was $\mathrm{NaCl}$ and Taste 2 was sucrose for the remainder of the rats. The order of conditioning to the compound and to the taste was counterbalanced in each of the groups. After conditioning, all of the rats were tested for their intakes of Tastes 1 and 2, which were presented on alternating sessions. Sucrose and salt were selected to confirm that odor potentiation of taste aversion learning can be obtained with tastes other than saccharin.

\section{Method}

\section{Subjects and Apparatus}

Subjects were 32 experimentally naive male Wistar rats weighing $290-350 \mathrm{~g}$. They were obtained from the same source and kept under the same conditions as those described in Experiment 1.

\section{Procedure}

Rats were adapted to the fluid deprivation schedule and trained to drink water in the test chambers described in Experiment 2. Amyl acetate $(.1 \%), .03 \mathrm{M} \mathrm{NaCl}$, and $.03 \mathrm{M}$ sucrose served as conditioning stimuli. Rats were then randomly allocated to one of four groups ( $n=8$ per group) that were counterbalanced for the taste conditioned in compound with the odor and for the order of conditioning to the compound and to the taste. Rats in Group $\mathrm{AA}+\mathrm{Suc} / \mathrm{NaCl}$ were injected with $\mathrm{LiCl}$ after exposure to a compound of anyl acetate and sucrose and after exposure to $\mathrm{NaCl}$, whereas rats in Group $\mathrm{AA}+\mathrm{NaCl} / \mathrm{Suc}$ were injected with $\mathrm{LiCl}$ after exposure to a compound of amyl acetate and $\mathrm{NaCl}$ and after exposure to sucrose. $\mathrm{LiCl}$ was injected within $3 \mathrm{~min}$ after exposure to the target fluid. Half of the rats in each of these groups were conditioned to the compound and then to the taste in isolation, and the remainder were conditioned to the taste and then to the compound. Seven days were allowed for recovery between the initial and second conditioning episodes and between the second conditioning episode and the start of testing. This was done to ensure a complete recovery of baseline intake before the second conditioning episode and the test. During the 7-day interval between conditioning sessions and for the first 7 days after the second conditioning session, rats were presented with water in the drinking chambers. Beginning on the 8th day after the second conditioning session, rats were tested for intake of the salt and sucrose solutions. The presentation of these tastes occurred in the same manner as that described in Experiment 2; thus rats were presented with water and then with the target taste. Each rat was tested on four occasions with $\mathrm{NaCl}$ and on four occasions with sucrose. Presentations of these tastes alternated across days, with the taste presented on the initial test counterbalanced across the various conditions.

\section{Results and Discussion}

The mean intakes averaged across both conditioning days were $4.5 \mathrm{ml}$ for sucrose, $5 \mathrm{ml}$ for salt, $3.3 \mathrm{ml}$ for sucrose + amyl acetate, and $4 \mathrm{ml}$ for salt + amyl acetate. Intake was $5.4 \mathrm{ml}$ on the initial conditioning day and $2.8 \mathrm{ml}$ on the $2 \mathrm{nd}$ day. This statistically significant $[t(31)=4.1]$ reduction in intake suggests that the aversion established on the initial conditioning day generalized to the substances used on the 2nd conditioning day, or that the initial illness enhanced neophobia to the cues presented on the 2nd conditioning day (Domjan, 1980).

However, the data of major interest are the percent intake of the salt and the sucrose relative to each water base- line intake across tests. These are shown in Figure 5. It is clear that taste aversion learning was potentiated when either the salt (Group AA $+\mathrm{NaCl} / \mathrm{Suc}$ ) or sucrose (Group $\mathrm{AA}+\mathrm{Suc} / \mathrm{NaCl}$ ) had been conditioned in compound with the odor (amyl acetate) in comparison with when the salt (Group AA $+\mathrm{Suc} / \mathrm{NaCl}$ ) or the sucrose (Group $\mathrm{AA}+\mathrm{NaCl} / \mathrm{Suc}$ ) had been conditioned in isolation. To analyze the data, a set of planned orthogonal contrasts was used to test for differences between groups, the taste conditioned in compound versus isolation, and trials. With $d f$ at 1,30 , and significance set at .05 , the critical $F$ value is 4.2 . The analysis revealed that there were no significant differences between the two groups of rats averaged over all test presentations of salt and sucrose $(F<$ 1.0). However, there was evidence for potentiation of taste aversion learning by the odor, since there were significant differences between test intake of the taste conditioned in compound with the odor versus intake in isolation $(F=9.2)$. There was a significant linear trend $(F=232)$ and a significant interaction between linear trend and whether the taste was conditioned in compound or in isolation $(F=14.6)$. In Figure 5 the significant linear trend confirms that the taste aversions extinguished across testing occasions, and the significant interaction shows that the taste conditioned in isolation extinguished more quickly than did the taste conditioned in compound with the odor. Thus, these results provide further evidence that a learned aversion to a taste is potentiated by an odor. They also show that this odor potentiation of a taste aversion is due to the co-occurrence of the odor and the taste in a reinforced compound rather than to the conditioning of an odor across the course of the experiment and the attendant possibility of generalization of an aversion from that odor to the taste (see Durlach \& Rescorla, 1980).

\section{GENERAL DISCUSSION}

These experiments have provided evidence that an odor (amyl acetate) mixed with the drinking fluid is just as effective as a taste (saccharin) in signaling illness, and that such an odor can potentiate taste aversion learning. This claim concerning the status of amyl acetate as an odor comes from the demonstration (Experiment 1) that olfactory bulbectomized rats were unimpaired on a go/no-go detection task based on a taste (sucrose), but, unlike controls, they were unable to use aqueous solutions of amyl acetate $(.1 \%)$ to regulate discriminative performance. Although with little or no gustatory properties, aqueous solutions of amyl acetate supported aversions in immediate and delayed toxiphobia conditioning procedures. The strengths of these odor aversions could be matched to those accruing to a taste by selection of appropriate concentrations of the odor and taste (Experiments 2 and 3 ). Finally, the presence of a strong odor cue for illness potentiated aversion learning to a weak taste (Experiment 4), and this potentiation depended on the taste being presented in compound with the odor (Ex- 


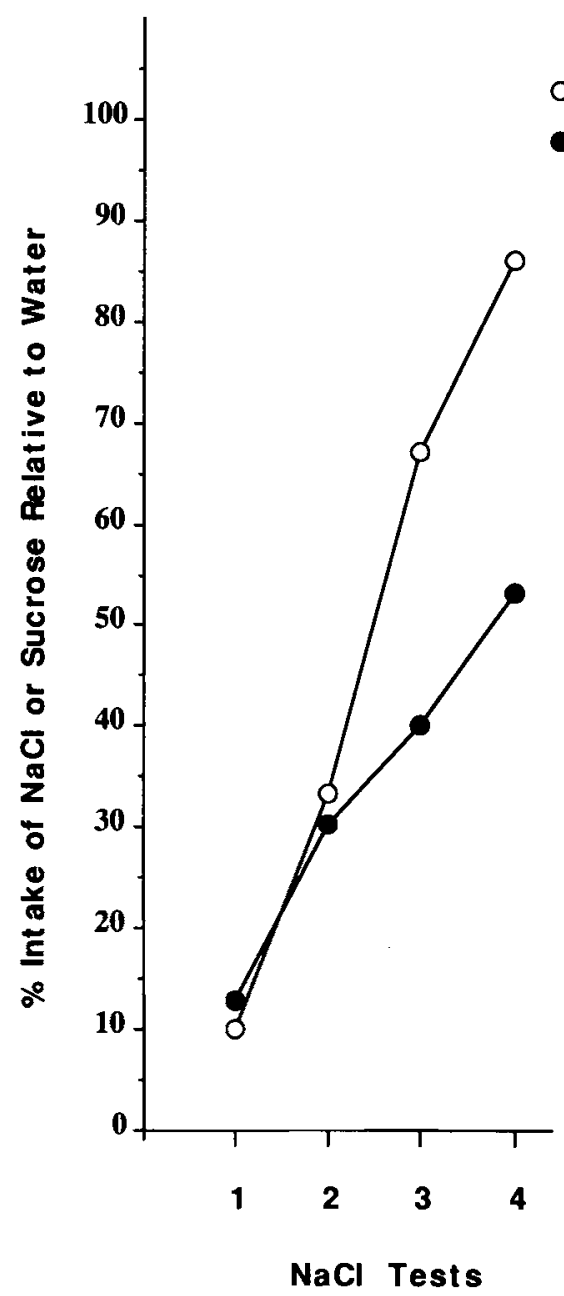

- AA+Suc/ $\mathrm{NaCl}$

- $\mathrm{AA}+\mathrm{NaCl} / \mathrm{Suc}$

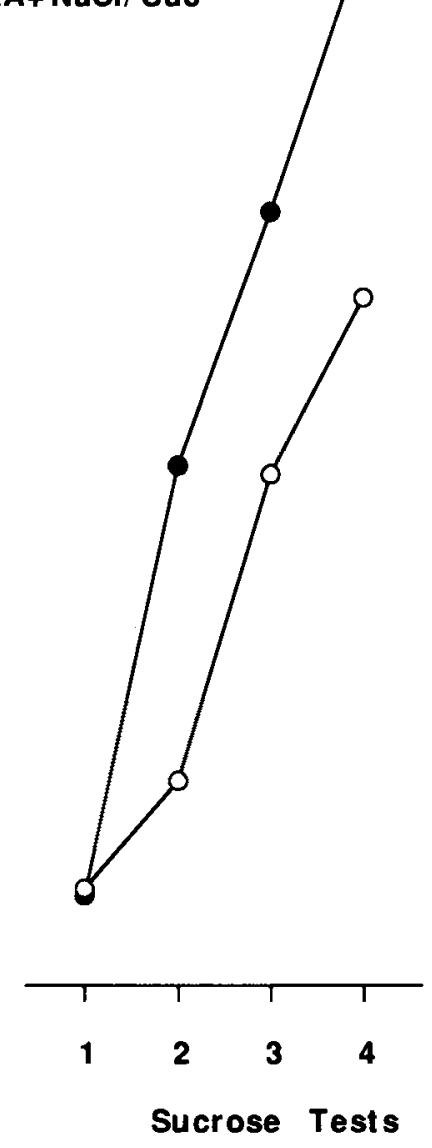

Figure 5. Experiment 5. Intakes of $\mathrm{NaCl}$ and sucrose expressed as percentages of water intake across tests. $\mathrm{NaCl}$ and sucrose were presented on alternate days, and intake was calculated on the basis of each day's water intake. Rats in Group $\mathrm{AA}+\mathrm{Suc} / \mathrm{NaCl}$ were injected with $\mathrm{LiCl}$ after exposure to an odor-sucrose compound and to $\mathrm{NaCl}$, whereas rats in Group $\mathrm{AA}+\mathrm{NaCl}$ Suc were injected with $\mathrm{LiCl}$ after exposure to an odor- $\mathrm{NaCl}$ compound and to sucrose.

periment 5). These findings challenge the theory of food aversion learning proposed by Garcia and his associates (e.g., Garcia et al., 1985) - in particular, the claims that a taste CS is the critical cue for the internal or gut-defense system, and that a taste directs the role of olfaction in feeding.

Studies of the cue-to-consequence effect have been especially important in promoting the view that taste is the critical CS for changes in the internal system, such as those caused by the presence of toxins in the blood or gut. However, the demonstration that illness, rather than either audiovisual cues (Domjan \& Wilson, 1972; Garcia \& Koelling, 1966) or odor vapors (Rusiniak, Palmerino, Rice, Forthman, \& Garcia, 1982) selectively conditioned tastes does not in fact warrant the claim that taste is the critical CS for the internal or gut-defense system. Mack- intosh (1983), for example, has argued that such studies can be interpreted as showing that illness conditions aversions to intrinsic attributes of the ingesta in preference to the audiovisual or olfactory cues, which are typically spatially separated from the ingesta (but see Garcia, McGowan, Erwin, \& Koelling, 1968). Support for this argument has been provided by the demonstration that the effectiveness of an odor as a cue for illness depends on its location: An odor mixed with the ingesta was more effective than the same odor located in a cup surrounding the ingesta (Bouton et al., 1986). Mackintosh has also suggested that the various intrinsic attributes of the food or fluid consumed, not just its taste, constitute the critical CS for the internal system, so that nontaste attributes of the ingesta should be just as effective as its taste in signaling illness. This implication has been confirmed by 
the present demonstrations concerning the comparability of aqueous odors and a taste as a cue for immediate or delayed illness.

The ability of a taste to potentiate odor aversion learning (Durlach \& Rescorla, 1980; Rusiniak et al., 1979; Westbrook et al., 1983) is the basis for the claim that the presence of a taste gates an associated odor into the internal system, thereby imbuing that odor with tastelike properties. Therefore, potentiation must be asymmetrical: Taste can potentiate odor aversion learning, but odors cannot potentiate taste aversion learning. This reasoning has been supported by demonstrations of taste potentiation of odor aversion learning but odor overshadowing of taste aversion learning (Westbrook et al., 1983). However, it is important to note that the ability of a taste to potentiate odor aversion learning is critically dependent on the effectiveness of the odor when it is conditioned in isolation. For example, Bouton et al. (1986) found that a taste potentiated an aversion to an odor located in a cup surrounding the drinking spout but not to an odor mixed with the drinking water. These differences with respect to potentiation of odor aversion learning were due to the conditionability of the odor rather than to its spatial location. Thus, Bouton et al. reported that a taste potentiated aversion learning to an odor in the drinking fluid if the concentration of the odor was reduced enough that there was little conditioning to the odor presented in isolation. These findings imply that previous failures to observe potentiation of taste aversion learning by a concomitantly present odor (e.g., Westbrook et al., 1983) may have been due to the use of tastes that were highly effective cues for illness. This implication is supported by the present demonstration of odor potentiation of taste aversion learning when the taste was weakly associable with illness, but not when it was strongly associable.

More generally, the pattern of results just described suggests that two conditions must be met for the potentiation of aversion learning. The first of these is the presence in an averted compound of a cue that is strongly associable with illness. This suggestion is supported by reports that taste potentiation of context aversion learning depends critically on the effectiveness of the taste as a cue for illness (Best, Batson, Meachum, Brown, \& Ringer, 1985; Best \& Meachum, 1986). Specifically, preconditioning exposures to a taste reduce not only the effectiveness of that taste as a cue for illness but also its ability to potentiate context aversion learning. This suggestion has also received support from the present demonstrations that an aqueous odor is an effective cue for illness and that such an odor can potentiate taste aversion learning. The second condition that must be met for the occurrence of potentiation is the presence in the averted compound of a weak cue for illness. Previous studies have used a weak odor or context (e.g., Best et al., 1985) in this role, but the findings reported here show that a weak taste can also serve as the to-be-potentiated cue.
The conditions just described for the occurrence of potentiation are consistent with an explanation for this phenomenon couched in terms of within-event learning (Durlach \& Rescorla, 1980). This explanation holds that the associations formed between the elements ( $\mathrm{S} 1$ and S2) of a simultaneous compound can contribute to the test performance shown to S1. More specifically, administration of a toxin subsequent to the presentation of a compound composed of a weak (S1) and a strong (S2) cue results in the conditioning of a weak aversion to $S 1$ and a strong aversion to $\mathrm{S} 2$. However, the association formed between $\mathrm{S} 1$ and $\mathrm{S} 2$ during the compound presentation enables $\mathrm{S} 1$ to activate the memory of the strongly averted S2, thereby adding to the control over ingestive behavior exerted by $\mathrm{S} 1$. This explanation of potentiation, in contrast to the sensory-and-gate analysis, does not identify S1 with an odor nor S2 with a taste. Rather, it emphasizes that potentiation depends on the formation of within-event associations between weak and strong cues for illness. The present findings suggest that this description has some generality, since these conditions were met by using a compound composed of a weak taste as $\mathrm{S} 1$ and a strong aqueous odor as $\mathbf{S} 2$.

The fact that odor stimuli may be at least as effective as tastes in illness-induced aversion learning also calls into question the neural mechanisms presumed to mediate the claimed advantage of taste in the gut-defense system. Specifically, this advantage of taste has been held to lie in the intimate association between taste and general visceral afferents at the level of the nucleus of the solitary tract (NTS) and, perhaps, other brainstem areas that monitor the gastrointestinal system (Garcia et al., 1972; Garcia et al., 1974; Garcia, Rusiniak, Keifer, \& BermudezRattoni, 1982). The present results suggest that the validity of this assumption can be maintained only to the extent that odor stimuli have a similarly privileged access to this visceral afferent system. On anatomical grounds, this is clearly not the case. Furthermore, there appears to be no support for the notion that acquisition of a conditioned taste aversion (CTA) involves convergence of gustatory and visceral afferents in NTS. Although rats with a high collicular brain stem transection can detect and discriminate tastants, they appear to be unable to acquire a conditioned taste aversion (Grill, 1985). As Grill (p. 85) stated, "In spite of repeated assertions that the NTS constitutes the neural basis of taste-illness association, there is currently no behavioral data to support an integration of taste and visceral afferent signals that is sufficient to produce behavioral aspects of CTAs within the NTS." Indeed, it appears that the amygdala, a structure that receives both gustatory and olfactory inputs, may play a critical role in acquisition of aversions (Yamamoto, Shimura, Sako, Yasoshima, \& Sakai, 1994).

Finally, it should be noted that there may be sensory interactions between tastes and odors in the mouth that create the percept of a flavor for the rat just as they do for humans (Murphy \& Cain, 1980; Murphy, Cain, \& Barto- 
shuk, 1977). Indeed, under natural conditions, the "taste" of most, if not all, foods the rat encounters would in fact constitute a flavor resulting from the combination of gustatory, olfactory, and, perhaps, trigeminal stimuli. Because the flavor, and not just the gustatory component, would serve to identify the foodstuff, it would be more adaptive for the proposed gut-defense system to be particularly sensitive to each of these components or the flavor they produce. In line with these suggestions, one might argue that the flavor resulting from exposure to an intraoral compound composed of a weak S1 (odor or taste) and a strong S2 (taste or odor) constitutes a more effective cue for illness than would the weak S1, so that rats conditioned to the compound acquire a stronger aversion to the flavor than do rats conditioned to the weak S1. The strong aversion conditioned to the flavor would then provoke greater suppression of intake to its component S1 via generalization than would the suppression that resulted from pairing S1 with illness. An implication of this explanation is that increasing the effectiveness of $\mathrm{S} 1$ as a cue for illness will reduce the differences between the test intakes of $\mathrm{S} 1$ among rats conditioned to $\mathrm{S} 1$ in isolation or in compound with S2. Just such an effect was observed here, since increases in the concentration of S1 reduced the potentiation of $S 1$ by $S 2$.

In summary, the effectiveness of odors in the mouth as cues for immediate or delayed illness, together with the ability of such an odor to potentiate taste aversion learning, suggests that odors in the mouth will share other properties of tastes in food aversion learning. For example, rats may select an odor in the mouth, rather than an audiovisual CS, as a cue for illness, but select an audiovisual cue, rather than that odor, as a signal for footshock. Such cue-to-consequence effects remain to be examined, but the present findings clearly indicate that rats can use odors in the mouth to signal the availability of fluid or illness. The ability to associate these retronasal odors with illness constitutes a simple explanation for the rat in the story told by Garcia and Rusiniak (1980). The rat had used distal odor cues to detect the food whose ingestion resulted in its various intrinsic attributes (taste, odor, or flavor) being associated with illness. The rat subsequently avoids the distal smell of that food because of its similarity to the averted retronasal odor or to the flavor.

\section{REFERENCES}

BARKER, L. M. (1976). CS duration, amount, and concentration effects in conditioning taste aversions. Learning \& Motivation, 7, 265-273.

Best, M. R., Batson, J. D., Meachum, C. L., Brown, E. R., \& Ringer, M. (1985). Characteristics of taste-mediated environmental potentiation in rats. Learning \& Motivation, 16, 190-209.

Best, M. R., \& MEACHUM, C. L. (1986). The effect of stimulus preexposure on taste-mediated environmental conditioning: Potentiation and overshadowing. Animal Learning \& Behavior, 14, 1-5.

Bouton, M. E., Jones, D. L., McPhillips, S. A., \& SwartzentruBER, D. (1986). Potentiation and overshadowing in odor-aversion learning: Role of method of odor presentation, the distal-proximal cue distinction and the conditionability of odor. Learning \& Motivation, 17, 115-138.
Brosvic, G., \& SLotnick, B. M. (1986). Absolute and intensity-difference taste thresholds in the rat: Evaluation of an automated multi-channel gustometer. Physiology \& Behavior, 38, 711-717.

DOMJAN, M. (1980). Ingestional aversion learning: Unique and general processes. In J. Rosenblatt, R. Hinde, C. Beer, \& M. Busnel (Eds.), Advances in the study of behavior (Vol. 2, pp. 275-336). New York: Academic Press.

DOMJAN, M. (1983). Biological constraints on instrumental and classical conditioning: Implications for general process theory. In G. H. Bower (Ed.), The psychology of learning and motivation (Vol. 17, pp. 215-277). New York: Academic Press.

Domjan, M., \& WiLsON, N. E. (1972). Specificity of cue to consequence in aversion learning in the rat. Psychonomic Science, 26, 143-145.

DraGoIN, W. B. (1971). Conditioning and extinction of taste aversions with variations in intensity of the CS and UCS in two strains of rats. Psychonomic Science, 22, 303-305.

DURLACH, P. J., \& ResCorla, R. A. (1980). Potentiation rather than overshadowing in flavor-aversion learning: An analysis in terms of within compound associations. Journal of Experimental Psychology: Animal Behavior Processes, 6, 175-187.

Field, B., \& SLOTNICK, B. M. (1987). An inexpensive multi-purpose amplifier for behavioral studies. Physiology \& Behavior, 40, 127-129.

GarCia, J., HANKINS, W. G., \& RUSiNIAK, K. W. (1974). Behavioral regulations of the milieu interne in man and rat. Science, 185, 824-831.

GarCia, J., \& KoElling, R. (1966). Relation of cue to consequence in avoidance learning. Psychonomic Science, 4, 123-124.

Garcia, J., Lasiter, P. S., Bermudez-Rattoni, F., \& Deems, D. A. (1985). A general theory of aversion learning. In N. S. Braveman \& P. Bronstein (Eds.), Experimental assessments and clinical applications of conditioned food aversions (Annals of the New York Academy of Sciences, Vol. 443, pp. 8-21). New York: New York Academy of Sciences.

Garcia, J., McGowan, B. K., Erwin, F. R., \& Koelling, R. A. (1968). Cues: Their effectiveness as a function of the reinforcer. Science, $\mathbf{1 6 0}$, 794-795.

Garcia, J., McGowan, B. K., \& Green, K. F. (1972). Biological constraints on conditioning. In A. H. Black \& W. F. Prokasy (Eds.), Classical conditioning II: Current research and theory (pp. 3-27). New York: Appleton-Century-Crofts.

GaRCIA, J., \& RUSiniaK, K. W. (1980). What the nose learns from the mouth. In D. Muller-Schwarze \& R. M. Silverstein (Eds.), Chemical signals: Vertebrates and aquatic invertebrates (pp. 141-156). New York: Plenum.

Garcia, J., Rusiniak, K. W., Keifer, S. W., \& Bermudez-Rattoni, F. (1982). The neural integration of feeding and drinking habits. In C. D. Woody (Ed.), Conditioning: Representation of involved neural functions (pp. 567-579). New York: Plenum.

GrILL, H. J. (1985). Introduction: Physiological mechanisms in conditioned taste aversions. In N. S. Braveman \& P. Bronstein (Eds.), Experimental assessments and clinical applications of conditioned food aversions (Annals of the New York Academy of Sciences, Vol. 443, pp. 67-88). New York: New York Academy of Sciences.

KUCHARSKI, D., \& SPEAR, N. E. (1985). Potentiation and overshadowing in preweanling and adult rats. Journal of Experimental Psychology: Animal Behavior Processes, 11, 15-34.

LoLordo, V. M., \& Droungas, A. (1989). Selective associations and adaptive specializations: Taste aversions and phobias. In S. B. Klein \& R. Mowrer (Eds.), Contemporary learning theories: Instrumental conditioning theory and the impact of biological constraints on learning (pp. 145-179). Hillsdale, NJ: Erlbaum.

Mackintosh, N. J. (1983). Conditioning and associative learning. New York: Oxford University Press.

Murphy, C., \& CaIN, W. S. (1980). Taste and olfaction: Independence vs. interaction. Physiology \& Behavior, 24, 601-605.

Murphy, C., CaIN, W. S., \& Bartoshuk, L. M. (1977). Mutual action of taste and olfaction. Sensory Processes, 1, 204-211.

Nachman, M., \& Ashe, J. H. (1973). Learned taste aversions in rats as a function of dosage, concentration, and route of administrations of LiCl. Physiology \& Behavior, 10, 73-78.

Palmerino, C. C., Rusiniak, K., \& GarCia, J. (1980). Flavor-illness 
aversions: The peculiar roles of odor and taste in memory for poison. Science, 208, 753-755.

Panhuber, H. (1982). Effect of odor quality and intensity on conditioned odor aversion learning in the rat. Physiology \& Behavior, 28, 149-154.

Rusiniak, K. W., Hankins, W. G., Garcia, J., \& Brett, L. P. (1979). Flavor-illness aversions: Potentiation of odor by taste in rats. Behavioral \& Neural Biology, 25, 1-17.

Rusiniak, K. W., Palmerino, C. C., Rice, A. G., Forthman, D. L., \& GarCIA, J. (1982). Flavor-illness aversions: Potentiation of odor by taste with toxin but not shock in rats. Journal of Comparative \& Physiological Psychology, 96, 527-539.
TAUKULIS, H. K. (1974). Odor aversions produced over long CS-US delays. Behavioral Biology, 10, 505-510.

Westbrook, R. F., Homewood, J., Horn, K., \& Clarke, J. C. (1983). Flavour-odour compound conditioning: Odour potentiation and flavour attenuation. Quarterly Journal of Experimental Psychology, 35B, 13-33.

Yamamoto, T., Shimura, T., Sako, N., Yasoshima, Y., \& Sakai, N. (1994). Neural substrates for conditioned taste aversion in the rat. Behavioural Brain Research, 65, 123-137.

(Manuscript received November 20, 1996; revision accepted for publication February 26, 1997.) 